\title{
Melatonin Improves Diabetes-Induced Foetal Growth Retardation in Rats
}

\author{
L. A. Olayaki ${ }^{1}$, A. O. Soladoye ${ }^{1}$ and O. O. Ojo ${ }^{2}$ \\ ${ }^{1}$ Department of Physiology, Faculty of Basic Medical Sciences, College of Health Sciences, University of Ilorin, \\ Ilorin, Nigeria \\ ${ }^{2}$ School of Biomedical Sciences, Faculty of Life and Health Sciences, University of Ulster, Coleraine, United Kingdom
}

Received: September 19, 2014; Accepted: January 20, 2015

\begin{abstract}
The aim of the present study was to investigate the effect of oral melatonin administration on foetal growth retardation, utero-placental antioxidant enzymes activities and lipid peroxidation in experimental diabetic rats. Twenty pregnant rats were divided into four groups of five rats each. Diabetes mellitus was induced by a single intraperitoneal administration of $120 \mathrm{mg} / \mathrm{kg}$ body weight of alloxan. From gestational day 5 to $19,5 \mathrm{mg} / \mathrm{kg}$ and $10 \mathrm{mg} / \mathrm{kg}$ of oral melatonin were administered to the rats with clearly manifested gestational diabetes. On the 19th day of gestation, the rats were sacrificed by cervical dislocation and placental, foetal and uterine tissues were harvested for estimation of tissue glutathione peroxidase (GPx) activity and malondialdehyde (MDA) levels. Foetal weight, foetal size, placental and plasma glucose were also determined. Results showed that, in diabetic rats, foetal growth retardation was associated with a significant reduction in placental and uterine antioxidant enzymes (GPx) activities $(\mathrm{P}<0.001)$ and increased lipid peroxidation as evidenced by raised MDA concentration $(\mathrm{P}<0.05)$. Treatment with oral melatonin significantly improved the foetal weight, placental and uterine antioxidant enzymes activities as well as reduced lipid peroxidation, without affecting the degree of hyperglycaemia. Effects of melatonin on foetal growth are presumed to be dependent on its ability to improve uteroplacental antioxidant enzymes activities and reduce lipid peroxidation.
\end{abstract}

Key words: Gestational diabetes, uteroplacental, melatonin, glutathione peroxidise, malondialdehyde

\section{Introduction}

Despite the fact that perinatal mortality has dramatically declined over the past decades, the incidence of malformations has remained unchanged. Congenital malformations represent the single most important cause of perinatal mortality or severe morbidity in diabetic pregnancy (Cederberg et al., 2001). The pathogenesis of diabetic embryopathy is multifactorial (Kucera, 1971). In addition to maternal serum glucose levels, studies have shown that factors such as serum levels of triglycerides, $\beta$-hydroxybutyrate, branch-chain amino acids, creatinine, HbAlc, arachidonic acid, reactive oxygen species and somatomedin inhibitors are associated with embryonic dysmorphogenesis (Buchanan et al., 1994; Styrud et al., 1995). Despite recent advances in the management of gestational diabetes, the disease still remains a significant threat during pregnancy with an increased risk of malformation and still birth (Evans, 2009). Obesity and gestational diabetes are characterised by insulin resistance and metabolic derangements resulting from oxidative stress and protein glycation leading to impaired endothelial function, vascular inflammation and haemostasis. These have been reported to give rise to microcirculatory impairment and abnormal placental function leading to increased foetal morbidity and stillbirth (Mondestin et al., 2002). In addition to the increased incidence of congenital malformations associated with diabetic pregnancy, human and laboratory studies have shown the retarded growth in foetuses of diabetic mother (Mills, 1982; Pedersen and MolstedPedersen, 1981).

Previous studies showed that diabetes-induced congenital malformations could be prevented with treatment of antioxidants such as vitamins $\mathrm{C}$, vitamin $\mathrm{E}$

Correspondence to: Luqman A. Olayaki, Tel.+2348052750165; E-mail: olayaki@unilorin.edu.ng 
and folic acid. (Wentzel et al., 1997 ; Cederberg et al., 2001). While the cellular mechanism of the diabetic embryopathy is not completely understood, a number of possible teratological processes have been suggested, based on the experimental studies. Pregnancy and diabetes have been reported to decrease antioxidant activities in rats (Szaleczky et al., 1999).

$\mathrm{N}$-Acetyl-5-methoxytryptamine, commonly known as melatonin, is a hormone produced by a wide range of organisms including animals, plants and microbes. In vertebrates, melatonin is produced primarily by the pineal gland. While most of the biological effects of melatonin are exhibited through the activation of the melatonin receptors (Boutin et al., 2005), studies have also reported its free radical scavenging (Tan et al., 2002) and indirect antioxidative activities (Reiter et al., 2000; Rodriquez et $a l ., 2004)$. In this study, we investigated the effect of oral melatonin on foetal growth retardation, uteroplacental antioxidant enzymes activities and lipid peroxidation in rats with alloxan-induced diabetes.

\section{Materials and Methods}

Experimental animals: Foetuses were obtained from Wistar albino rats maintained in the Department of Biochemistry, Faculty of Life Sciences, University of Ilorin. Rats were fed a commercial pelleted diet (Bendel feeds, Edo State, Nigeria) and had free access to food and tap water. They were maintained at an ambient temperature of $25^{\circ} \mathrm{C}$ with a $12 \mathrm{hr}$ light/dark cycle. To initiate mating, each female rat was placed in the same cage with a male and conception was verified by the presence of sperm in the vaginal smear. All experimental procedures were approved by the Animal Ethical Committee of the Faculty of Basic Medical Sciences, University of Ilorin, Nigeria.

Induction of diabetes and treatment with melatonin: Induction of diabetes was performed in a subset of female rats by intraperitoneal injection of $120 \mathrm{mg} / \mathrm{kg}$ alloxan (Sigma St. Louis MO, USA) 1 week before mating commenced (3 weeks before conception). Diabetic status was confirmed 1 week after injection by serum glucose level $\geq 250 \mathrm{mg} / \mathrm{dl}$ using AccuCheck glucometer (Roche Diagnostics, Indianapolis, IN, USA). Non-diabetic control rats were injected with saline. Pregnant rats were administered saline (control) or graded doses of melatonin
(Sigma, $5 \mathrm{mg} / \mathrm{kg}$ and $10 \mathrm{mg} / \mathrm{kg}$ ) dissolved in absolute ethanol and dissolved in $0.9 \% \mathrm{NaCl}(1.9 \mathrm{w} / \mathrm{v})$ with oral cannula from day 5 to day 19 of gestation.

Collection of terminal blood samples and organs: On day $19^{\text {th }}$ day of gestation, rats were sacrificed by means of cervical dislocation. Blood samples were collected by cardiac puncture into EDTA bottles and centrifuged at $3,000 \mathrm{rpm}$ for $20 \mathrm{~min}$ at $4^{\circ} \mathrm{C}$, and plasma was stored below $-20^{\circ} \mathrm{C}$ until used. Uteri of the animals were for the measurement of placental weight as well as foetal weight and size. Sections of excised uteri (100mg) were transferred to $2 \mathrm{ml}$ of ice-cold sucrose solution $(0.3 \mathrm{M})$ prior to homogenization at a speed of $3000 \mathrm{~g}$ for 10 minutes at $4^{\circ} \mathrm{C}$. The supernatants were collected for the measurement of antioxidant enzymes activities.

Estimation of glutathione peroxidase (GPx) activity: The specific activity of glutathione peroxidase was determined using the glutathione peroxidase cellular activity assay kit from Automation Inc., Calabasas, CA, USA, following the manufacturer's instructions. This protocol, which is based on the report of Paglia and Valentine (1967), requires cumene hydroperoxide as a substrate and a five-fold dilution of homogenate. Absorbance was monitored at $340 \mathrm{~nm}$ for $3 \mathrm{~min}$ and enzyme activity was reported in $\mathrm{U} / \mathrm{mg}$ of protein.

Determination of lipid peroxidation: Tissue malonaldedyde (MDA) levels were estimated as described by Ohkawa et al, (1979). Part of iced homogenized tissues was placed in a total volume of cold $3 \mathrm{ml} / 100 \mathrm{mMkcl}$ plus $0.003 \mathrm{M}$ EDTA and homogenised. Homogenates were centrifuged at $600 \mathrm{~g}$ for $15 \mathrm{~min}$. Then, 400 microliters of supernatant was added to $0.2 \mathrm{ml} 8.1 \%$ SDS, $1.5 \mathrm{ml} \mathrm{20 \%}$ acetic acid (PH 3.5), $1.5 \mathrm{ml} \mathrm{0.8 \%}$ thiobarbituric acid and $0.6 \mathrm{ml}$ water. The solution was heated to $95^{\circ} \mathrm{C}$ for 60 minutes. After addition of $1.0 \mathrm{ml}$ water and $5.0 \mathrm{ml}$ of $\mathrm{n}$ butanol-pyridine mixture (15:1, vol/vol), the mixture was vigorously shaken and centrifuged at 2,000g for 15 minutes. The absorbance of the upper layer was read at $532 \mathrm{~nm}$ with Acurex Microplate Reader. MDA bisdimethyl acetal was be used as the external standard. Results were expressed as nanomoles MDA per milligram protein. The intra-assay variability was determined in five sets of triplicate samples, and the coefficient of variation given. 
Statistical analysis: All data are expressed as mean \pm SEM. Statistical differences among the groups were calculated using analysis of variance (ANOVA) followed by Ducan's multiple range test (SPSS 20.0 version, Chicago, IL, USA). Differences with $\mathrm{P}<0.05$ were considered significant.

\section{Results and Discussion}

Maternal plasma glucose levels, litter weight, litter size and plancenta weight in normal and melatonintreated pregnant rats with alloxan-induced diabetes: A significant $(\mathrm{P}<0.05)$ increase in fasting maternal plasma glucose levels was observed in mice with alloxan-induced diabetes $(260-270 \mathrm{mg} / \mathrm{dl})$ compared with non-diabetic control rats $(80-95 \mathrm{mg} / \mathrm{dl})$ and treatment with melatonin produced no significant difference in plasma glucose levels (Figure 1A). Litter size of diabetic untreated rats reduced by $161 \%(\mathrm{P}<0.001)$ compared with normal rats. However, administration of melatonin improved litter size by 3.7 -fold $(5 \mathrm{mg} / \mathrm{kg}$ body weight, $\mathrm{P}<0.001)$ and 3.9 -fold $(10 \mathrm{mg} / \mathrm{kg}$ body weight, $\mathrm{P}<0.001)$ (Figure $1 \mathrm{~B})$. Similarly, injection of alloxan produced a $49 \%(\mathrm{P}<0.001)$ reduction in litter weight compared with normal rats while treatment with 5 or $10 \mathrm{mg} / \mathrm{kg}$ body weight of melatonin significantly $(\mathrm{P}<0.05)$ improved litter weight by 1.5 - and 1.6 -fold respectively (Figure 1C). Placental weight was slightly elevated $(0.67 \pm 0.06)$ in diabetic untreated rats compared with normal rats $(0.49 \pm 0.04)$ (Figure 1D). Placenta weight in melatonin-treated diabetic rats reduced by $13 \%(5 \mathrm{mg} / \mathrm{kg}$ bw, $\mathrm{P}<0.05)$ and $16 \%(5 \mathrm{mg} / \mathrm{kg}$ bw, $\mathrm{P}<0.05)$.

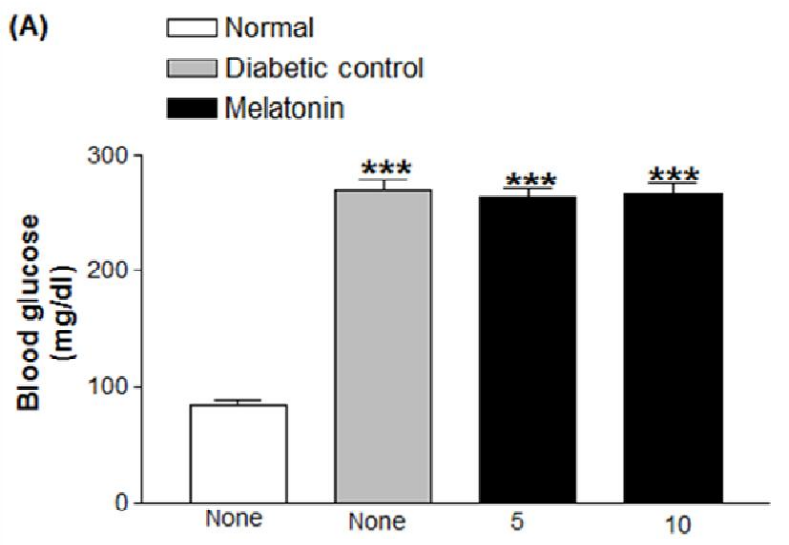

Concentration of melatonin ( $\mathrm{mg} / \mathrm{kg} \mathrm{bw})$

(C)
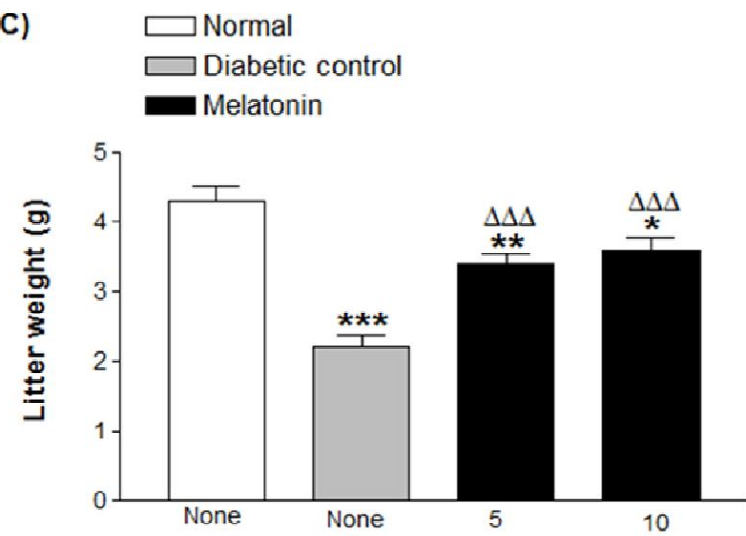

Concentration of melatonin $(\mathrm{mg} / \mathrm{kg} \mathrm{bw})$
(B)
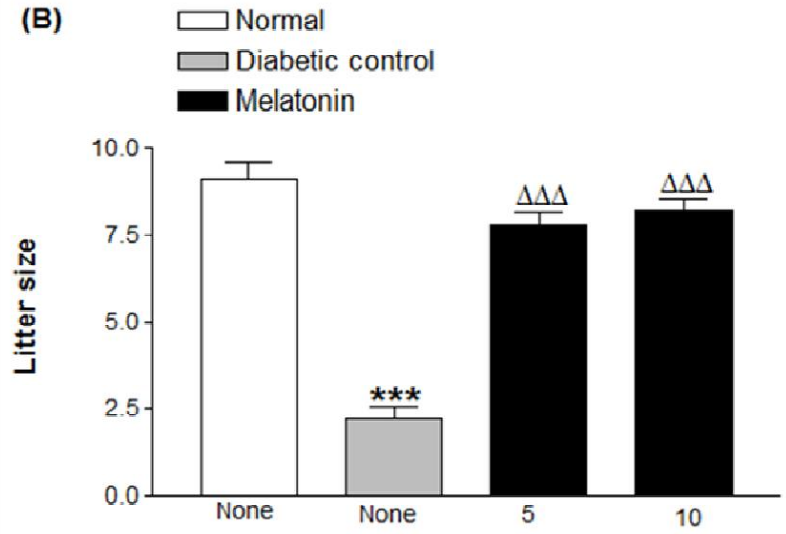

Concentration of melatonin $(\mathrm{mg} / \mathrm{kg}$ bw)

(D)
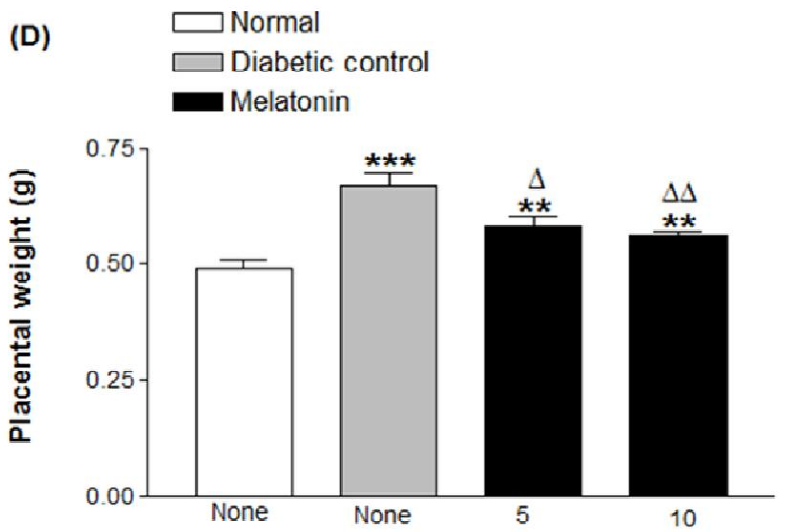

Concentration of melatonin $(\mathrm{mg} / \mathrm{kg} \mathrm{bw})$

Figure 1. Plasma glucose (A), litter size (B), litter weight (C) and placental weight (D) in normal and diabetic rats treated with saline or graded doses of melatonin. Values are expressed as the mean $\pm \operatorname{SEM}(\mathrm{n}=5)$. ${ }^{*} \mathrm{P}<0.05, * * \mathrm{P}<0.01, * * * \mathrm{P}<0.001$ compared with normal rats. ${ }^{\Delta} \mathrm{P}<0.05,{ }^{\Delta \Delta} \mathrm{P}<0.01,{ }^{\Delta \Delta \Delta} \mathrm{P}<0.001$ compared with diabetic control rats. 
Glutathione peroxidase activity: Figure 2 showed a significant $(\mathrm{P}<0.001)$ reduction in uterine $(38 \%)$ and placental $(47 \%)$ glutathione peroxidase activities in untreated diabetic pregnant rats compared with normal rats. However, melatonin administration $(5 \mathrm{mg} / \mathrm{kg}$ body weight) improved uterine and placental glutathione activities by $20 \% \quad(\mathrm{P}<0.01) \quad$ and $29 \% \quad(\mathrm{P}<0.05)$ respectively. Similarly, treatment with $10 \mathrm{mg} / \mathrm{kg}$ body weight melatonin produced $25 \%$ (uterine, $\mathrm{P}<0.01$ ) and $32 \%$ (placental, $\mathrm{P}<0.05$ ) improvement in glutathione peroxidase activity compared with diabetic untreated rats.

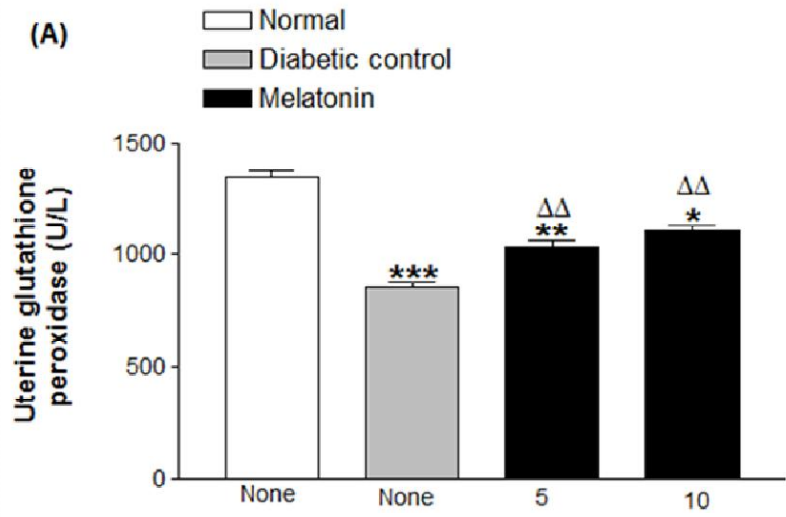

Concentration of melatonin $(\mathrm{mg} / \mathrm{kg} \mathrm{bw})$

(B)

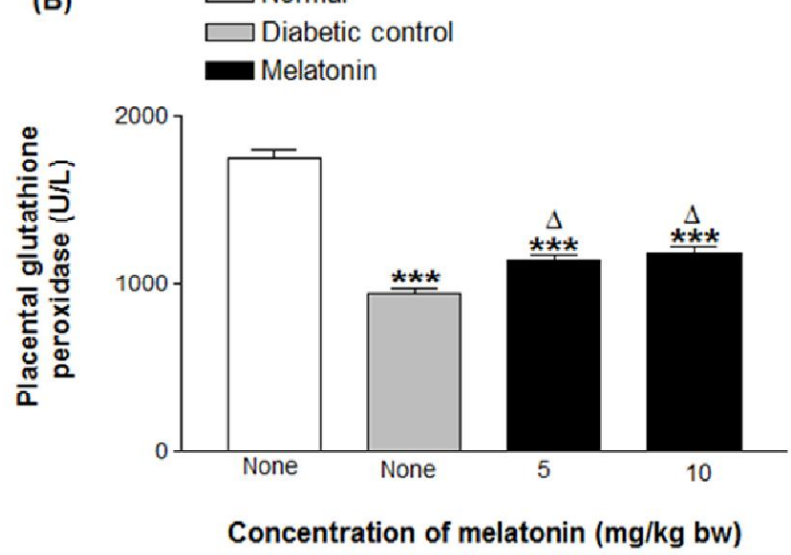

Figure 2. Effect of melatonin on uterine (A) and placental (B) glutathione peroxidase activity in normal and diabetic pregnant rats. Values are expressed as the mean \pm SEM $(\mathrm{n}=5) . \quad * \mathrm{P}<0.05, \quad * * \mathrm{P}<0.01, \quad * * * \mathrm{P}<0.001$ compared with normal rats. ${ }^{\Delta} \mathrm{P}<0.05,{ }^{\Delta \Lambda} \mathrm{P}<0.01$ compared with diabetic control rats.

Organ malondialdehyde (MDA) levels: Results presented in Figure 3 showed the effects of melatonin treatment on organ MDA levels in rats with alloxan- induced diabetes. Uterine and placental MDA levels were increased by $20 \%(\mathrm{P}<0.05)$ and $39 \%(\mathrm{P}<0.01)$ respectively in diabetic untreated rats. While treatment with graded doses of melatonin completely reversed elevated uterine MDA levels (Figure 3A), the increase observed in placenta MDA levels was reduced by significantly reversed $20 \%(\mathrm{P}<0.05)$ and $25 \%(\mathrm{P}<0.01)$ in rats treated with 5 and $10 \mathrm{mg} / \mathrm{kg}$ bw of melatonin respectively (Figure 3B).

(A)
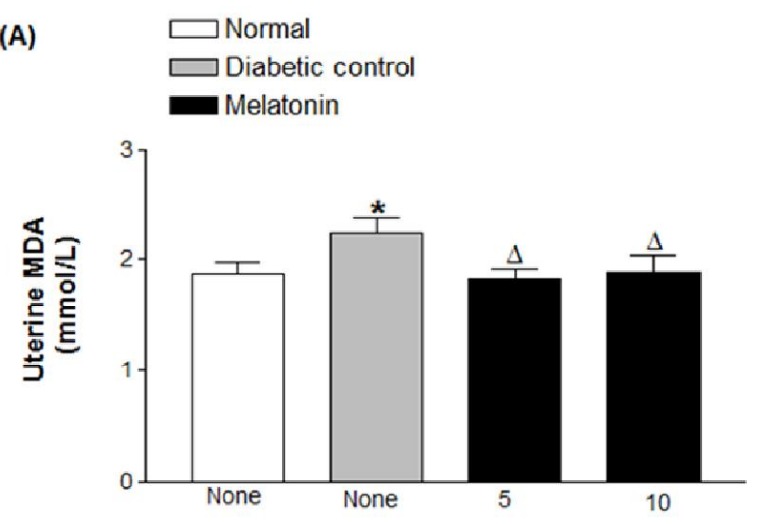

Concentration of melatonin $(\mathrm{mg} / \mathrm{kg} \mathrm{bw})$

(B)
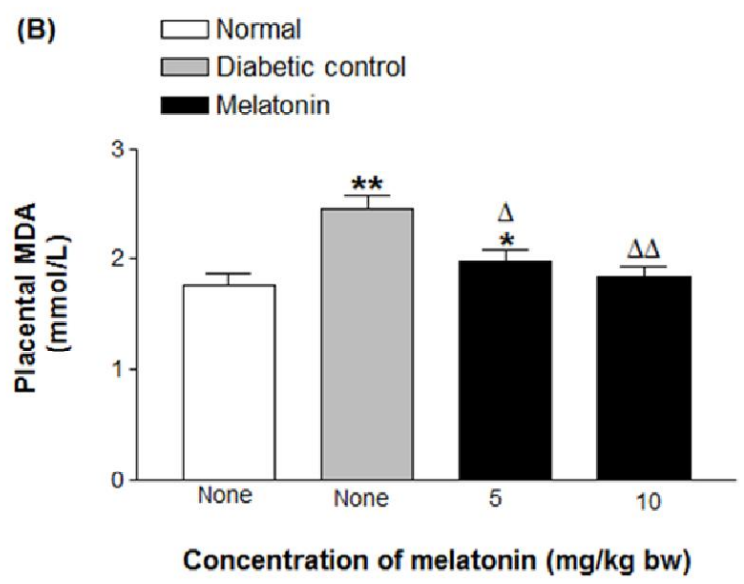

Figure 3. Effect of melatonin on uterine (A) and placental (B) malondialdehyde (MDA) levels in normal and diabetic pregnant rats. Values are expressed as the mean \pm SEM $(\mathrm{n}=5) . \quad{ }^{*} \mathrm{P}<0.05,{ }^{*} \mathrm{P}<0.01$, compared with normal rats. ${ }^{\Delta} \mathrm{P}<0.05,{ }^{\Delta \Delta} \mathrm{P}<0.01$ compared with diabetic control rats.

The antioxidant activity of melatonin was evaluated in this study using its effect on glutathione peroxidase (GPx) malondialdehyde (MDA) as a marker. Glutathione peroxidase promotes intracellular defence by catalysing decomposition of reactive oxygen species (Szaleczky et 
al., 1999) and is a key indicator of oxidative stress (Goyal et al., 2011). Reduced GPx activities observed in alloxaninduced rats in this study indicates higher levels of oxidative stress and is consistent with reports of previous human and animal studies with diabetes (Goyal et al., 2011). Protein glycation is a known consequence of hyperglycemia. Therefore, reduced GPx activities observed in this study may result from possible changes in structure and function of the enzyme in the presence of high concentration of glucose. Hyperglycemia could also affect the concentration of cofactors required for optimum functions of antioxidant enzymes. This observation is consistent with the reports of Wohaieb and Godin (1987) and Sukalski et al., (1993), which assessed glutathione peroxidase and superoxide dismutase activities in the liver tissue of diabetic rats. In the present study, administration of melatonin raised the level of antioxidants activity in both diabetic and non-diabetic rats. Several studies have previously reported relationships between antioxidant system and diabetic malformations (Wentzel et al., 1997; Sakamaki et al., 1999 and Cederberg et al., 2001). For instance, Sakamaki et al. (1999) implicated glutathionedependent antioxidant system in the diabetic embryonic malformations while Wentzel et al. (1997) and Cederberg et al. (2001) reported that diabetes-induced congenital malformations could be prevented by treatment with antioxidant agents such as vitamin $\mathrm{C}$, vitamin $\mathrm{E}$ and folic acid.

Oxidative stress is caused by free radicals or radicalgenerating agents at concentration that overwhelms natural radical-blocking or scavenging mechanisms (Block et al., 2002). Cigarette smoking and conditions such as diabetes mellitus and oxidative burst from activated macrophages have been known to induce oxidative stress. Endogenous effects of oxidative stress include damage to DNA, proteins and lipids and many other physiologically important chemicals; underscoring the importance of overwhelming the body's antioxidant defence system in the pathogenesis of many diseases (Halliwell and Guteridge, 1990). The present study showed that the concentrations of MDA, one of the biomarkers of oxidative damage, increased during gestational diabetes. However, administration of melatonin reduced MDA generation in the uterus and placental tissues. Diabetes has been associated with excess reactive oxygen species which is a cause of increased lipid peroxidation (Eriksson et al.,
1996; Wentzel et al., 1997). The free radical scavenging ability of melatonin is due to activities of two of its metabolites, namely, $\mathrm{N}^{1}$-acetyl- $\mathrm{N}^{2}$-formyl-5-methoxykynuramine (AFMK) and $\mathrm{N}^{1}$-acetyl-5-methoxykynuramine (AMK) (Tan et al., 2002; Ressmeyer et al., 2003). The superb antioxidative effects of melatonin have also been attributed to its ability to diffuse through biological membrane with ease and exert its actions in almost every cell in the body.

This study showed that melatonin had no effect on maternal blood glucose, indicating that though melatonin exhibited strong antioxidant and free radicals scavenging actions, its action is devoid of beneficial hypoglycaemic effects. This observation is consistent with the lack of hypoglycaemic effects reported for other antioxidants, such as vitamins $\mathrm{C}$ and $\mathrm{E}$, in rats with gestational diabetes (Cederberg et al., 2001; Siman and Eriksson, 1997). However, improved litter size and weight observed in this study also indicate that beneficial effects of melatonin may include prevention of foetal malformations or morbidity in gestational diabetes.

\section{References}

Block, G., Dietrich, M., Norkus, E.P., Morrow, J.D., Hudes, M., Caan, B. and Packer, L. 2002. Factors associated with oxidative stress in human populations. Am. J. Epidemiol. 156, 274-285.

Boutin, J.A., Audinot, V., Ferry, G., Delagrange, P. 2005. Molecular tools to study melatonin pathways and actions. Trends Pharmacol. Sci. 26, 412-419.

Buchanan, T.A., Denno, K.M., Sipos, G.F. and Sadler, T.W. 1994. In vitro evidence for a multifactorial etiology with little contribution from glucose per se. Diabetes 43, 656660 .

Cederberg, J., Siman, C.M. and Eriksson, A.J. 2001. Combined treatment with vitamin $\mathrm{E}$ and vitamin $\mathrm{C}$ decreases oxidative stress and improves fetal outcome in experimental diabetic pregnancy. Pediatr. Res. 49, 755-762.

Eriksson, U.J., Borg, L.A.H., Forsberg, H., Simán, C.M., Suzuki, N. and Yang, X. 1996. Can foetal loss be prevented? The biochemical basis of diabetic embryopathy. Diabetes Rev. 4, 49-69.

Evans, M.J. 2009. Diabetes and pregnancy: a review of pathology. Br. J. Diabetes Vasc. Dis. 9, 201-206.

Goyal, R., Singhai M., and Faizy A.F. 2011. Glutathione peroxidase activity in obese and nonobese diabetic patients and role of hyperglycemia in oxidative stress. J. Midlife Health, 2, 72-76. 
Halliwell, B. and Gutteridge, J.M.C. 1990. Role of free radicals and catalytic metal ions in human disease: an overview. Methods Enzymol. 186, 1-85.

Kucera, J. 1971. Rate and type of congenital anomalies among offsprings of diabetic women. J. Reprod. Med. 7, 61-70.

Mills, J.L. 1982. Malformations in infants of diabetic mothers. Teratology 25, 385-394

Mondestin, M.A.J., Ananth, C.V., Smulian J.C. and Vintzileos, A.M. 2002. Birth weight and foetal death in the United States: the effect of maternal diabetes during pregnancy. Am. J. Obstet Gynaecol. 187, 922-926.

Ohkawa, H., Ohishi, N. and Yagi, K. 1979. Assay for lipid peroxides in animal tissues by thiobarbituric acid reaction. Anal. Biochem. 95, 351-358.

Paglia, D.E. and Valentine, W.N. 1967. Studies on the avantitaue and gualitative characterization of erythrocyte glutathione peroxidase. J. Lab. Clin. Med. 70, 158-69.

Pedersen, J.F. and Mølsted-Pedersen, L. 1981. Early growth delay detected by ultrasound marks increased risk for congenital malformation in diabetic pregnancy. $\mathrm{Br}$. Med. $J$. 283, 269-271.

Reiter, R.J., Tan, D.X., Osuna, C. And Gitto, E. 2000. Actions of melatonin in the reduction of oxidative stress: a review. $J$. Biomed. Sci. 7, 444-58

Ressmeyer, A.R., Mayo, J.C., Zelosko, V., Sainz, R.M., Tan, D.X., Poeggeler, B., Antolin, I., Zsizsik, B.K., Reiter, R.J. and Hardeland, R. 2003. Antioxidant properties of the melatonin metabolite $\mathrm{N}^{1}$-acetyl-5-methoxykynuramine (AMK): scavenging of free radicals and prevention of protein destruction. Redox Rep. 8, 205-213.

Rodriquez, C., Mayo, J.C., Sainz R.M., Antolin I., Herrera F., Martin V., Reiter R.J. 2004. Regulation of antioxidant enzymes: a significant role for melatonin. J. Pineal Res. 29, 94-99
Styrud, J., Thunberg, L., Nybacka, O. and Eriksson, C.J. 1995. Correlations between maternal and deranged development in the offspring of normal and diabetic rats. Pediatr. Res. 37, 343-353.

Sakamaki, H., Akazawa, S., Ishibashi, M., Izumino, K., Abiru, N., Kondo, H., Takino, H., Yamasaki, H., Yamaguchi, Y., Kondo, T. and Nagataki, S. 1999. Diabetes-induced embryopathy and gluta-thione-dependent antioxidant system (Abstract). Diabetes 46 (Suppl. 1), 88A.

Simán, C.M. and Eriksson U.J. 1997. Malformations in the offspring of diabetic rats are prevented by supplementation of the maternal diet with vitamin C. Diabetologia 40, 14161424.

Sukalski, K.A., Pinto, K.A. and Berntson, J.L. 1993. Decreased susceptibility of liver mitichondria from diabetic rats to oxidative damage and associated increase in alpha tocopherol. Free Radical Biol. Med. 14, 57-65.

Szaleczky, E., Prechl, J., Fehér, J. and Somogyi, A. 1999. Alterations in enzymatic antioxidant defence in diabetes mellitus- a rational approach. Postgrad Med. J. 75, 13-17.

Tan, D.X., Reiter, R.J., Manchester, L.C., Yan, M.T., El-Sawi, M., Sainz, R.M., Mayo, J.C., Kohen, R., Allegra, M. and Hardeland, R. 2002. Chemmical and physical properties and potential mechanisms: melatonin as a broad-spectrum antioxidant and free radicals scavenger. Curr. Top. Med. Chem. 2, 181-198.

Wentzel, P., Thunberg, L.A and Eriksson, U.J. 1997. Teratogenic effect of diabetic serum is prevented by supplementation of superoxide dismutase and $N$-acetylcysteine in rat embryo culture. Diabetologia 40, 7-14.

Wohaieb, S.A. and Godin, D.V. 1987. Alterations in free radical tissue defense mechanisms in streptozotocin-induced diabetes in rat. Diabetes 36, 1014-1018. 